\title{
Crestamento gomoso do caule da melancia: Etiologia, epidemiologia e medidas de controle
}

\author{
Gil Rodrigues dos Santos ${ }^{1 *}$, Evelynne Urzêdo Leão ${ }^{1}$, Henrique Guilhon de Castro ${ }^{1}$, Ildon \\ Rodrigues do Nascimento ${ }^{1}$, Renato de Almeida Sarmento ${ }^{2}$ e Rúbia Borges Cruz Sarmento- \\ Brum $^{1}$
}

${ }^{1}$ Departamento de Agronomia; Universidade Federal do Tocantins; 77402-970; Gurupi - TO - Brasil.

${ }^{2}$ Departamento de Engenharia Florestal; Universidade Federal do Tocantins; 77402-970; Gurupi - TO - Brasil.

\begin{abstract}
The stem gummy blight (Didymella bryoniae) is one of the most important fungal diseases of the crop of the watermelon, because it causes damping off of the seedlings, lesions on leaves and cotyledons, and formation of cankers on stems and stalks. The fungus survives in the absence of the host on or beneath the soil, in sick crop residues, in other cultivated curcubitáceas, weeds or seeds. To control the disease is recommended the adoption of integrated management techniques, including cultural practices, chemical control and genetic control with the use of tolerant and / or resistant genotypes and other measures. This review aims to address the information to organize knowledge obtained in national and international literature on the gummy stem blight in watermelon crop. We tried to relate the aspects of etiology, epidemiology and controlling measures of D. bryoniae. It was noted that after several studies had been conducted so far, you must search for further information about the biology of the pathogen and the management of the disease in the field.
\end{abstract}

Key words: Stem canker, Didymella bryoniae, Citrullus lanatus

\section{INTRODUÇÃO}

A melancia [Citrullus lanatus (Thunb.) Matsum e Nakai)] pertence à família das cucurbitáceas, originária do continente africano é considerada uma das mais importantes olerícolas produzidas e comercializadas no Brasil, não somente pelas suas características nutricionais como também pelo seu valor comercial.

De acordo com Santos et al. (2005d) a melancia, assim como a maioria das culturas pode ser infectada por dezenas de patógenos, que causam os mais diferenciados sintomas. Além das doenças bióticas, existem as abióticas, que também podem causar destruição total da cultura, caso não se adotem medidas preventivas.

Dentre as doenças fúngicas, o crestamento gomoso do caule, causado por Didymella bryoniae (Auersw) Rehm é uma das principais (Santos et al., 2006a), pois causa tombamento das plântulas, lesões circulares nas folhas e formação de cancros no caule e nas hastes, que é um sintoma característico da doença. Para o controle da doença recomenda-se a adoção de técnicas de manejo integrado, incluindo práticas culturais, controle químico e controle genético com a utilização de genótipos tolerantes e/ou resistentes, além de outras medidas.

No Brasil, a doença vem despertando preocupação nos perímetros irrigados da região norte (Santos et al., 2005b) e nordeste do Brasil (Dias et al. 1996), e em outros países como nos Estados Unidos (Schenck, 1968; Sitterly e Keinath, 1996; Keinath e Duthie, 1998; Everts, 1999), e no Caribe tropical (Bala e Hosein, 1986).

Para que o cultivo tenha êxito, é necessário desenvolver medidas de controle a fim de prevenir a ocorrência de epidemias. Esta revisão tem por objetivo abordar informações da literatura nacional e internacional sobre o crestamento gomoso do caule na cultura da melancia.

\section{Crestamento gomoso do caule}

Conhecido também como podridão gomosa, podridão negra, podridão de micosferela e cancro das hastes, o crestamento gomoso do caule encontra-se presente em todas as regiões 
produtoras de curcubitáceas, principalmente em regiões de clima tropical, onde é considerada uma doença importante da cultura da melancia, provocando perdas que podem chegar a $60 \%$, quando não se adotam medidas de controle eficientes (Santos et al., 2005d).

\section{Etiologia}

O patógeno agente do crestamento gomoso do caule é o fungo Didymella bryoniae (Auersw.) Rehn, parasita necrotrófico facultativo de plantas da família Cucurbitaceae (Svedelius, 1990). Pertence a subdivisão Ascomicotyna, ordem Dothiales e classe Coelomycetes (Krugner e Bacchi, 1995). Foi descrito pela primeira vez na França em 1891, na fase anamórfica, com o nome de Ascochyta cucumis Fautr \& Roum, e mais tarde na fase teleomórfica como Didymella melonis Pass (Wiant, 1945; Chiu e Walker, 1949). Atualmente, a fase teleomórfica recebe a denominação Didymella bryoniae (Auersw.) Rehn. A primeira descrição e ilustração da fase teleomórfica do fungo Didymella bryoniae (Auersw.) Rehn foi feita no Brasil por Santos \& Café Filho (2006a) no Projeto Formoso, no Estado do Tocantins.

Os picnídios escuros que caracterizam o estádio anamórfico Ascochyta cucumis Fautr \& Roum, desenvolvem-se na superfície das lesões foliares, nas hastes e nos frutos. No interior, formam-se conídios cilíndricos e providos de um septo (Duarte, 2003). As estruturas do estádio teleomórfico são mais raras e formam-se principalmente em áreas necrosadas da haste. Caracterizam-se por peritécios (pseudotécias) escuros, contendo, no interior, ascos e ascósporos bicelulados, hialinos, arredondados na extremidade e com uma constrição à altura do septo. A célula superior apresenta-se mais longa que a inferior. Embora tenham sido observadas variações em isolados do fungo, ainda não foi identificada especialização fisiológica em relação ao hospedeiro. As colônias do fungo apresentam micélio aéreo branco e micélio verde oliva quando o substrato utilizado é batata-dextrose-ágar (BDA) (Keinath et al., 1995).

\section{Epidemiologia}

$O$ fungo sobrevive na ausência do hospedeiro sobre e/ou abaixo do solo, nos restos culturais doentes de curcubitáceas, plantas daninhas ou em sementes. O patógeno é muito resistente ao sol e outras intempéries, permanecendo viável por vários anos no solo (um a três anos) e nos restos culturais. Frutos doentes geralmente apresentam sementes infectadas, que constituem o principal meio de disseminação e sobrevivência do fungo (Santos et al., 2005d).

O inóculo primário é constituído por conídios ou ascósporos, que são disseminados em curta distância, principalmente por respingos de chuva, água da irrigação, máquinas e contato com os implementos agrícolas e as ferramentas durante os tratos culturais (Vida et al., 2004; Santos et al., 2005d). Cardoso et al. (1974) relatam que a relação entre o surgimento dos ascósporos e o aparecimento dos sintomas indica que a disseminação do patógeno ocorre principalmente pelos esporos da fase perfeita. Entretanto, Kurozawa et al. (2005) cita que ambos os tipos de esporos, sexuais e assexuais, são capazes de atuar como fonte de inóculo primário.

Café-Filho et al. (2010) estudando o efeito da distância inicial do inóculo na intensidade do crestamento gomoso do caule em um plantio comercial de melancia naturalmente infectado, observaram que os valores máximos da doença foram alcançados mais precocemente nas áreas próximas aos focos e que a incidência atingiu valores máximos mais rapidamente que a severidade. Constataram que a doença progrediu em taxas similares, independente da distância radial a partir do foco inicial.

Temperaturas de 20 a $30{ }^{\circ} \mathrm{C}$, com um ótimo em torno de $25^{\circ} \mathrm{C}$ e umidade relativa do ar em torno de $95 \%$ são favoráveis ao desenvolvimento do fungo no hospedeiro. Porém, a doença pode ocorrer em locais onde a umidade é inferior a $40 \%$ durante o dia e há molhamento foliar à noite. A presença de lâmina de água, durante algumas horas, nas folhas e nos ramos é suficiente para que o fungo penetre por aberturas naturais e por ferimentos provocados pelo homem, insetos ou que ocorrem durante o crescimento devido ao atrito do solo (Santos et al., 2005d). O progresso do crestamento gomoso e as perdas provocadas pelo patógeno na cultura da melancia foram avaliados por Santos et al., (2005b) em dois ensaios de campo no Estado do Tocantins, com inoculação artificial de D. bryoniae. Neste estudo, a doença progrediu exponencialmente e atingiu 26,5\% da área foliar no tratamento sem aplicação de fungicida. $\mathrm{O}$ aumento da severidade da doença na área foliar resultou na redução de 19,2\% na produtividade. 


\section{Sintomatologia}

Os sintomas provocados podem diferir de acordo com a planta hospedeira afetada e da fase em que se encontra a cultura. Em plântulas, ocorrem manchas escurecidas e arredondadas nos cotilédones, que passam ao hipocótilo, necrosa-o e circunda-o, causando posterior tombamento. Nas folhas as lesões, inicialmente, apresentam-se com aspecto aquoso, depois progridem para uma mancha necrótica circular, podendo de acordo com a evolução dos sintomas, ocasionar a morte da plântula (Santos et al., 2005d).

Em plantas adultas, os sintomas variam de acordo com o órgão afetado. Nas folhas, ocorrem manchas circulares de coloração marrom-escura a preta, às vezes com o halo amarelado, que se tornam quebradiças, formando buracos no centro da folha. Normalmente, as lesões iniciam-se nas margens, progredindo em direção ao centro do limbo foliar, resultando no crestamento da folha (Kurozawa et al., 2005).

Nas hastes e suas ramificações, bem como no pecíolo, aparecem manchas encharcadas que depois necrosam, adquirindo uma coloração pardo-escura. Inicialmente arredondadas, as manchas torna-se elípticas e circundam o órgão afetado. A lesão pode exsudar uma goma parda acinzentada que, ao secar, apresenta na superfície vários pontos negros, que são os picnídios do patógeno. É muito comum que as lesões de caule e haste evoluam para um cancro, vindo a causar o fendilhamento do córtex, expondo os tecidos internos da planta. A lesão circunda a coroa, causando o murchamento que pode levar a planta à morte. Posteriormente, essas manchas tornam marrons e exsudam uma goma, do mesmo modo que nas hastes, deixando a mostra os sinais do fungo na forma de picnídios (Santos et al., 2005d).

Mesmo sendo menos freqüente, com o passar do tempo, e de acordo com as condições ambientais, a lesão pode aprofundar e causar um apodrecimento parcial do fruto, que passa apresentar lesões necróticas circulares e de coloração escura (Santos et al., 2005d).

\section{Medidas de controle}

Para o controle da doença, recomenda-se a adoção de técnicas de manejo integrado, incluindo práticas culturais, controle químico e controle genético com a utilização de genótipos tolerantes e/ou resistentes, além de outras medidas.

\section{Manejo integrado}

No manejo integrado do crestamento gomoso do caule recomenda-se evitar o plantio na mesma área por três vezes consecutivas, fazer rotação com culturas de outras famílias, eliminação de plantas daninhas e curcubitáceas hospedeiras, evitar o excesso de umidade no solo, evitar irrigação por aspersão, utilizar sementes sadias, usar espaçamento adequado de modo a não permitir o fechamento excessivo das ramas, evitar ferimentos nas plantas durante os tratos culturais, não fazer a prática da amontoa, controlar os insetos que danificam as folhas (Santos et al., 2005d). Na cultura do melão rendilhado, tem sido recomendado o uso da enxertia com a utilização de porta enxertos resistentes (Silva, 2010). Recomenda-se ainda utilizar genótipos resistentes e/ou tolerantes e tratar as sementes com fungicidas protetores misturados com os sistêmicos (Santos et al., 2005d).

O manejo da adubação, constitui uma importante alternativa para reduzir a severidade das doenças. Neste contexto, Santos et al., (2009a) analisando a influência de doses de nitrogênio na severidade do crestamento gomoso e a produtividade da melancia, observaram que houve um incremento na produtividade com o aumento das doses de nitrogênio até $40 \mathrm{~kg} \cdot \mathrm{ha}^{-1}$. A avaliação da severidade da doença demonstrou que a aplicação de dosagens crescentes de nitrogênio resulta em um favorecimento à infecção pelo patógeno. A partir do tratamento de $80 \mathrm{~kg}$ de nitrogênio a infecção se intensificou e ocorreu diminuição da produtividade e no peso médio dos frutos.

Santos et al. (2010), estudando a influência de fontes e doses de silício no controle do crestamento gomoso do caule e na produtividade da melancia, observaram que a menor severidade da doença foi observada quando aplicou-se a maior dosagem de silício (3 t.ha ${ }^{-1}$ ). Ressaltaram que a aplicação de silício via solo na forma de pó apresentou melhores resultados que a aplicação via foliar na forma líqüida.

\section{Controle químico}

O controle crestamento gomoso do caule em campo tem sido feito principalmente com o uso de fungicidas (Keinath, 1995). Porém, na grande maioria das vezes o controle químico tem apresentado baixa eficiência, devida a rápida infecção das folhas pelo patógeno, quando as condições são favoráveis (Arny e Rowe, 1991; 
Van Steekelenburg, 1995). Esse fato ocorre devido a resistência e/ou insensibilidade do fungo a determinados princípios ativos, entre os quais o grupo químico dos benzimidazóis e estrobilurina (Malathrakis e Vakalounakis, 1983; Keinath, 2009).

Santos et al. (2005c) em condições de campo, testaram fungicidas isolados e em mistura, e observaram que a testemunha apresentou os maiores níveis de intensidade da doença não diferindo estatisticamente dos tratamentos com os fungicidas Tebuconazole, Tiofanato metílico, Difenoconazole e Carbendazim. Por outro lado, as misturas de Tiofanato Metílico + Clorotalonil, Mancozeb + Difenoconazole, Trifloxistrobina + Propiconazole e os produtos isolados Mancozeb e Oxicloreto de cobre reduziram significativamente a doença.

Santos et al. (2006b) relataram resistência in vitro de $D$. bryoniae a fungicidas do grupo químico dos benzimidazóis, onde $81 \%$ dos 31 isolados testados mostraram-se altamente resistentes ao Tiofanato Metílico na dose recomendada, concordando com os dados obtidos em outros países como os EUA (Keinath e Zitter, 1998), Grécia (Malathrakis e Vakalounakis, 1983), Holanda (Van Steekelenburg,1987) e Japão (Kato et al., 1984).

\section{Controle genético}

A utilização de genótipos tolerantes e/ou resistentes é uma das medidas mais eficientes para o controle de doenças. Porém, apesar de existir fontes de resistência genética a essa doença, no Brasil são poucos os trabalhos realizados e os resultados observados não são satisfatórios para a adoção no campo.

Sowell e Pointer (1962) identificaram o genótipo PI 189225 como fonte de resistência ao crestamento gomoso do caule na melancia. Norton e Cosper (1985) confirmaram esta resistência e comentaram que além deste, o genótipo PI 271778 possui potencial para utilização em programas de melhoramento através de retrocruzamentos que resultarão no lançamento de cultivares de melancia resistentes ao crestamento e outras doenças. No Brasil, em um dos ensaios de Dias et al. (1996), o acesso PI 189225 apresentou apenas $16,6 \%$ e $41,7 \%$ de plantas respectivamente resistentes e medianamente resistentes. Mesmo assim, diferiu significativamente de Crimson Sweet, que foi classificada como altamente suscetível. Desta forma, observa-se falta de estabilidade na resistência de PI 189225 a D. bryoniae indicando que o material estaria segregando para esta característica.

Santos et al. (2005a) analisando a reação de genótipos de melancia a $D$. bryoniae obtiveram resultados favoráveis com o híbrido Riviera, que manteve os menores níveis de doença nas folhas quando comparada com outros genótipos até aos 89 dias após o plantio (DAP). Porém os autores ressaltaram que no híbrido a doença se manifestou mais tarde, mantendo-se em níveis baixos em épocas importantes, demonstrando assim que essa resistência ainda é parcial e a doença pode alcançar índices elevados ao final do ciclo.

Santos et al. (2009b) avaliando diferentes genótipos de melão ao crestamento gomoso do caule em casa de vegetação e campo, observaram que os genótipos testados em casa de vegetação apresentaram variação significativa quanto aos níveis de resistência. E em condições de campo, sob inóculo natural, os genótipos Taslaki e Sary Juliabi mostraram-se mais suscetíveis à infecção pelo patógeno nas folhas, diferindo significativamente dos demais genótipos, sendo os menores níveis de suscetibilidade verificados nos genótipos Perlita Busle S1, Valenciano Elíptico, Glaver, MR1 e 2526.

\section{Outras medidas}

O uso de óleos vegetais, com efeito, fungitóxico também tem sido utilizado como possível alternativa de controle. Fiori et al. (2000) analisando o efeito fungitóxico do extrato bruto de folhas e óleos essenciais de Eucalyptus citriodora, Achillea millefolium, Ageratum conyzoides e Cymbopogon citratus observaram que os extratos e os óleos essenciais mostraram-se eficientes na inibição do crescimento micelial e na redução da germinação dos esporos de $D$. bryoniae. O mesmo foi observado por Bankole e Joda (2004), que utilizando o óleo essencial de Cymbopogon citratus observaram a inibição de $100 \%$ do crescimento micelial de patógeno.

O controle biológico com a utilização de microrganismos antagonistas apresenta grande potencial no controle de fitopatógenos de solo, como a $D$. bryoniae. O fungo antagonista Trichoderma sp. foi testado por Pérez et al. (2010), na cultivar Charleston Gray durante dois anos consecutivos. Os autores observaram redução da severidade da doença e maiores rendimentos de frutos nos tratamentos com a utilização de Trichoderma sp. aplicados na semente e via foliar a cada 15 dias. 
Rizzo et al. (2003), avaliando a ação de Acibenzolar-s-Methyl (BTH) isolado e em combinação com fungicidas no controle do cancro da haste em melão rendilhado, constataram que a combinação Difenoconazole + BTH proporcionou melhor controle da doença.

Nga et al. (2010), ao identificar rizobactérias de raízes de melancia oriundas do Delta do Mekong no Vietnã, observaram que estas tinham potencial para proteger sistemicamente a planta contra $D$. bryoniae. Ao testar a capacidade antagônica in vitro destas bactérias, notaram que das 190 amostras, 68 foram capazes de inibir o patógeno pela produção de antibióticos. A bactéria Pseudomonas aeruginosa 231-1 foi selecionada e testada em campo, apresentando redução significativa da doença em dois anos consecutivos e um aumento no rendimento dos frutos. No intuito de elucidar os mecanismos envolvidos na proteção, foi estudada a infecção do patógeno em tratamento com e sem bactéria, e observou-se que a bactéria inibiu a penetração do patógeno e isso foi associado ao acúmulo de peróxido de hidrogênio, ao aumento da atividade da peroxidase e a ocorrência de novas isoformas da peroxidade, indicando resistência induzida.

Foi possível constatar que apesar de vários estudos terem sido realizados até o momento, deve-se buscar novas informações a respeito da biologia do patógeno bem como sobre o manejo da doença no campo.

\section{RESUMO}

O crestamento gomoso do caule (Didymella bryoniae) é uma das doenças fúngicas mais importantes da cultura da melancia, pois causa tombamento das plântulas, lesões nas folhas e cotilédones, e formação de cancros no caule e nas hastes. $\mathrm{O}$ fungo sobrevive na ausência do hospedeiro sobre e/ou abaixo do solo, nos restos culturais doentes, em outras curcubitáceas cultivadas, plantas daninhas ou em sementes. Para o controle da doença recomenda-se a adoção de técnicas de manejo integrado, incluindo práticas culturais, controle químico e controle genético com a utilização de genótipos tolerantes e/ou resistentes, além de outras medidas. Esta revisão tem por objetivo abordar informações da literatura nacional e internacional sobre o crestamento gomoso do caule na cultura da melancia. Procurou-se relatar os aspectos de etiologia, epidemiologia e medidas de controle de D. bryoniae. Foi possível constatar que apesar de vários estudos terem sido realizados até o momento, deve-se buscar novas informações a respeito da biologia do patógeno bem como sobre o manejo da doença no campo.
Palavras-chave: Cancro da haste, Didymella bryoniae, Citrullus lanatus

\section{REFERÊNCIAS}

Arny, C. J.; Rowe, R. C. (1991), Effects of temperature and duration of surface wetness on spore production and infection of cucumbers by Didymella bryoniae. Phytopathology, 81, 206-209.

Bala, G.; Hosein, F. (1986), Studies on gummy stem blight disease of cucurbits in Trinidad. Tropical Agriculture, 63, 195-197.

Bankole, S. A. e Joda, A. O. (2004), Effect of lemon grass (Cymbopogon citrates Stapf) powder and essential oil on mould deterioration and aflatoxin contamination of melon seeds (Colocynthis citrullus L.). African Journal of Biotechnology, 3, 52-59.

Café-Filho, A. C.; Santos, G. R.; Laranjeira, F. F. (2010), Temporal and spatial dynamics of watermelon gummy stem blight epidemics. European Journal Plant Pathology, 128, 473-482.

Cardoso, R. M. G.; Figueiredo, R. B.; Palazzo, D.; Martinez, J. A. (1974), Epidemiology of fruit rot (Mycosphaerella melonis, (Pass.) Chiu; J. C. Walker) on italian squash (Cucurbita pepo L). Arquivo do Institudo Biológico, 41, 35-37.

Chiu, W. F. e Walker, J. C. (1949), Physiology and pathogenicity of the cucurbit blackrot fungus. Journal of Agricultural Research, 78, 589-615.

Duarte, M. L. R. (2003), Doenças de plantas no Trópico Úmido brasileiro. II. Fruteiras nativas e exóticas. $1^{\text {a }}$ Ed. Brasília: EMBRAPA. 305p.

Dias, R. C. S.; Queiroz, M. A.; Menezes, M. (1996), Identificação de fontes de resistência em melancia a Didymella bryoniae. Horticultura Brasileira, 14, 15-17.

Everts, K.L. (1999), First report of benomyl resistance of Didymella bryoniae in Delaware and Maryland. Plant disease, 83, 304 - 304.

Fiori, A. C. G.; Schwan-Estrada, K. R. F.; Stangarlin, J. R.; Vida, J. B.; Scapim, C. A.; Cruz, M. E. S.; Pascholati, S. F. (2000), Antifungal Activity of Leaf Extracts and Essential Oils of some Medicinal Plants against Didymella 
bryoniae. Journal of Phytopathology, 148, 483487.

Kato, T.; Suzuki, K.; Takahashi, J.; Kamoshita, K. (1984), Negatively correlated cross-resistance between benzimidazole fungicides and methyl $\mathrm{N}$ (3-5-dichlorophenyl) carbamate. Journal Pesticide Science, 9, 489-495.

Keinath, A. P. (2009), Sensitivity to azoxystrobin in Didymella bryoniae isolates collected before and after field use of strobilurin fungicides. Pest Management Science, 65, 1090-6.

Keinath, A. P.; Duthie, I. A. (1998), Yield and quality reductions in watermelon due to anthracnose, gummy stem blight and black rot. Recent Research Developments in Plant Pathology, 2, 77-90.

Keinath, A. P.; Farnham, M. W.; Zitter, T. A. (1995), Morphological, pathological, and genetic differentiation of Didymellabryoniae and Phoma spp. Isolated from cucurbits. Phytopathology, 85, 364-369.

Keinath, A.P. e Zitter, T.A. (1998), Resistance to Benomyl and Thiophanate-methyl in Didymella bryoniae from South Carolina and New York. Plant Disease, 82, 479-84.

Krugner, T. L. e Bacchi, L. M. A. (1995), Fungos. In: Bergamin Filho, A; Kimati, H.; Amorim, L. (eds). Manual de fitopatologia princípios e conceitos. $3^{a}$ Ed. São Paulo: Agronômica Ceres, 1. 46-96.

Kurozawa, C.; Pavan, M. A.; Rezende, J. A. M. (2005), Doenças das cucurbitáceas. In: Kimati, H.; Amorim, L.; Rezende, J.A.M.; Bergamin Filho, A.; Camargo, L.E.A. Manual de Fitopatologia: Doenças das Plantas Cultivadas. $4^{\text {a }}$ Ed. São Paulo: Agronômica Ceres, 2, 293-310.

Malathrakis, N. E. e Vakalounakis, D. J. (1983), Resistance to benzimidazole fungicides in the gummy stem blight pathogen Didymella bryoniae on cucurbits. Plant Pathology, 32, 395-399.

Nga, N. T.; Giau, N. T.; Long, N. T.; Lübeck, M.; Shetty, N. P.; Neergaard, E.; Thuy, T. T.; Kim, P. V.; Jorgensen, H. J. (2010), Rhizobacterially induced protection of watermelon against
Didymella bryoniae. Journal of Applied Microbioly. 109, 567-82.

Norton, J. D. e Cosper, R. D. (1985), Breeding watermelons for disease resistance. Phytopathology, 75, $1178-1178$.

Pérez, J.; Martínez, B.; Rivas, E.; Moreno, M.; Díaz, M. E. (2010), Aplicación de Trichoderma para el control del tizón gomoso del tallo (Didymella bryoniae (Auersw) Rehm) en el cultivo de sandía (Citrullus vulgaris) Schrad (2010), In: II Taller Latinoamericano de Biocontrol de Fitopatógenos. Havana (Cuba). 49$72 \mathrm{p}$.

Rizzo, A. A. N.; Ferreira, M. R.; Braz, L. T. (2003), Ação de acibenzolar-s-methyl (BTH) isolado e em combinação com fungicidas no controle do cancro da haste em melão rendilhado. Horticultura Brasileira, 21, 238-240.

Santos, G. R. e Café-Filho, A. C. (2005a), Reação de genótipos de melancia ao crestamento gomoso do caule mela. Horticultura Brasileira, 23, 945950.

Santos, G. R. e Café Filho, A. C.(2006a), Ocorrência do crestamento gomoso do caule em melancia no Tocantins causado por Didymella bryoniae. Fitopatologia Brasileira, 31, 208-209.

Santos, G. R.; Café-Filho, A. C.; Leão, F. F.; César, M.; Fernandes, L. E. (2005b), Progresso do crestamento gomoso e perdas na cultura da melancia. Horticultura Brasileira, Brasília, 23, 228-232.

Santos, G. R.; Café-Filho, A. C.; Saboya, L. M. F. (2005c), Controle químico do crestamento gomoso do caule na cultura da melancia. Fitopatologia Brasileira, 30, 155-163.

Santos, G. R.; Café-Filho, A. C.; Reis, A. (2006b), Resistência de Didymella bryoniae a fungicidas no Brasil. Fitopatologia Brasileira, 31, 476-482.

Santos, G. R.; Castro Neto, M. D.; Almeida, H. S. M.; Ramos, L. N.; Sarmento, R. A.; Lima, S. O.; Erasmo, E. A. L. (2009a), Influência de doses de nitrogênio na severidade de doenças e na produtividade da melancia. Horticultura Brasileira, 27, 330-334. 
Santos, G. R.; Castro Neto, M. D.; Carvalho, A. R. S.; Fidelis, R. R.; Afférri, F. S. (2010), Fontes e doses de silício na severidade do crestamento gomoso e produtividade da melancia. Bioscience Journal, 26, 266-272.

Santos, G. R.; Castro Neto, M. D.; Ramos, L. N.; Café-Filho, A. C.; Reis, A.; Momenté, V. G.; Pelúzio, J. M.; Ignácio, M. (2009b), Reaction of melon genotypes to the gummy stem blight and the downy mildew. Horticultura Brasileira, 27, 160-165.

Santos, G. R.; Zambolim, L.; Resende, J. A. M.; Costa, H. (2005d), Manejo integrado de doenças da melancia. Viçosa, 70p.

Schenck, N. C. (1968), Epidemiology of gummy stem blight (Mycosphaerella citrulina) on watermelon: ascospore incidence and disease development. Phytopathology, 58, 1420-1422.

Silva, E. S. Porta-enxertos, concentrações de potássio na resistência à Didymella bryoniae e relações fisiológicas do meloeiro. Dissertação (Mestrado em Agronomia) - Universidade Estadual Paulista, 2010.

Sitterly, W. R.; Keinath, A. P. (1996), Gummy stem blight. In: Zitter, T. A.; Hopkins, D. L.; Thomas, C. E. Compendium of Cucurbit Diseases. The American Phytopathological Society. APS Press. St. Paul, Minnesota. 86p.
Sowell, G. Jr. e Pointer, G. R. (1962), Gummy stem blight resistance of introduced watermelons. Plant Disease Report, 46, 883-885.

Svedelius, G. (2002), Effects of environmental factors and leaf age on growth and infectivity of Didymella bryoniae. Mycological Research, 97, 885-889.

Van Steekelenburg, N. A. M. (1987), Resistance to benzimidazole and dicarboximide fungicides in Botrytis cinerea and Didymella bryoniae in cucumbers in the Netherlands. Mededelingen Faculteit Landbouwwetenschappen Rijksuniversiteit Gent, 52, 875-880.

Van Steekelemburg, N. A. M. (1995), Influence of humidity on incidence of Didymella bryoniae on cucumber leaves and growing points under controlled environmental conditions. Netherlands Journal of Plant Pathology, 91, 253-264.

Vida, J. B.; Tessmann, D. J.; Zambolim, L.; Verzignassi, J. R.; Brandão Filho, J. U. T. (2004), Controle da podridão gomosa em melão rendilhado em cultivo protegido por sanitização de ferramenta de poda. Fitopatologia Brasileira, 29, 626-630.

Wiant, J. S. (1945), Mycosphaerella black rot of cucurbits. Journal of agricultural Research, 71, 193-213. 